\title{
Room-Temperature Ionic Liquids with High Conductivities and Wide Electrochemical Windows
}

\author{
AUTHOR(S): \\ Matsumoto, Kazuhiko; Hagiwara, Rika; Ito, \\ Yasuhiko
}

\section{CITATION:}

Matsumoto, Kazuhiko ...[et al]. Room-Temperature Ionic Liquids with High Conductivities and Wide Electrochemical Windows. Electrochemical and Solid-State Letters 2004, 7(10): E41.

\section{ISSUE DATE:}

2004

URL:

http://hdl.handle.net/2433/254681

\section{RIGHT:}

This is the Accepted Manuscript version of an article accepted for publication in Electrochemical and Solid-State Letters. IOP Publishing Ltd is not responsible for any errors or omissions in this version of the manuscript or any version derived from it. The Version of Record is available online at https://doi.org/10.1149/1.1795613.; この論文は出版社版で ありません。引用の際には出版社版をご確認ご利用ください。;This is not the published version. Please cite only the published version. 
Room temperature ionic liquids with high conductivities and wide electrochemical windows: $\quad N$-alkyl- $N$-methylpyrrolidinium and $N$-alkyl- $N$-methylpiperidinium

\section{fluorohydrogenates}

Kazuhiko Matsumoto, ${ }^{\dagger}$ Rika Hagiwara, ${ }^{z^{*}}$ and Yasuhiko Ito ${ }^{* *}$

Graduate School of Energy Science, Kyoto University, Yoshida, Sakyo-ku, Kyoto

606-8501, Japan

* Electrochemical Society Active Member

** Electrochemical Society Fellow

${ }^{\dagger}$ Research Fellow of the Japan Society for the Promotion of Science

z E-mail: hagiwara@energy.kyoto-u.ac.jp; Tel: $\quad$ +81-75-753-5822; $\quad$ Fax:

$+81-75-753-5906$

Keyword: Room temperature ionic liquid, Room temperature molten salt, Fluorohydrogenate 
Novel room temperature ionic liquids (RTILs), $N$-alkyl- $N$-methylpyrrolidinium $\left(\mathrm{RMPyr}^{+}\right)$and $N$-alkyl- $N$-methylpiperidinium $\left(\mathrm{RMPip}^{+}\right)$fluorohydrogenates formulated by $\mathrm{RMPyr}(\mathrm{HF})_{2.3} \mathrm{~F}$ and $\mathrm{RMPip}(\mathrm{HF})_{2.3} \mathrm{~F}$ ( $\mathrm{R}=$ ethyl, propyl and butyl), have been synthesized by the reactions of the corresponding chlorides and anhydrous hydrogen fluoride. These RTILs exhibit relatively low viscosities (9.9 - 37.1 cP), high conductivities (12.3 - $74.6 \mathrm{mS} \mathrm{cm}^{-1}$ ) and wide electrochemical widows around $5 \mathrm{~V}$. The fluorohydrogenate salts of symmetric cations, $N, N$-dimethylpyrrolidinium $\left(\mathrm{DMPyr}^{+}\right)$ and $N, N$-dimethylpiperidinium $\left(\mathrm{DMPip}^{+}\right.$) obtained by evacuation at room temperature are solids, exhibiting the composition of DMPyrF-2HF and DMPipF-2HF which are probably DMPyr(HF $)_{2} \mathrm{~F}$ and DMPip(HF) $)_{2} \mathrm{~F}$. 


\section{Introduction}

Studies on room temperature ionic liquids (RTILs, also called room temperature molten salts) composed of alkylated ammonium cations and various chloro- or fluoroanions have been made for applications like electrolytes of batteries and electroplating baths as well as organic reaction solvents. ${ }^{1-3}$ The properties of RTILs such as nonflammability, nonvolatility, high chemical and thermal stability are preferable for these applications.

Salts of aromatic cations such as 1,3-dialkylimidazolium or 1-butylpyridinium often exhibit relatively low melting points and viscosities which lead to high conductivities, compared to the salts of $n$-tetraalkylammonium cations. On the other hand, dialkylpyrrolidinium salts recently reported possess relatively high melting points compared to the aromatic cation-based salts. ${ }^{4-7}$ The cation needs a long alkyl side-chain and combination with bis(trifluoromethylsulfonyl)amide anion to have a melting point of lower than room temperature. ${ }^{5}$ However, the extension of the alkyl side-chain on the ammonium cation results in lowering of its conductivity as well as the melting point. In the case of combination with an asymmetric anion, $\mathrm{N}\left(\mathrm{SO}_{2} \mathrm{CF}_{3}\right)\left(\mathrm{COCF}_{3}\right)^{-}$, even $N, N$-dimethylpyrrolidinium salt has a low melting point of $297 \mathrm{~K} .^{7}$ However, the viscosity of it is as high as $80 \mathrm{cP}$ at $298 \mathrm{~K}$. Alkylation of a part of the aromatic ring, for example the C2-position of 1,3-alkylimidazolium, somewhat improves the 
electrochemical stability. ${ }^{8,9}$ Even though, electrochemical stability of the nonaromatic cation is higher than that of the aromatic cation., ${ }^{4,5}$ A series of 1-alkyl-3-methylimidazolium fluorohydrogenates $\quad\left(\mathrm{RMIm}(\mathrm{HF})_{2.3} \mathrm{Fs}, \quad \mathrm{RMIm}=\right.$ 1-alkyl-3-methylimidazolium) reported recently are composed of $\mathrm{RMIm}^{+}$and $(\mathrm{HF})_{n} \mathrm{~F}^{-10-15}$ They exhibit high conductivities compared to the other RTILs (for example, $10^{2} \mathrm{mS} \mathrm{cm}^{-1}$ for 1-ethyl-3-methylimidazolium fluorohydrogenate (EMIm(HF) $\left.{ }_{2.3} \mathrm{~F}\right)$ ) and low melting points and/or glass transition temperatures (208 and $148 \mathrm{~K}$ for $\left.\mathrm{EMIm}(\mathrm{HF})_{2.3} \mathrm{~F}\right){ }^{12}$ Although the electrochemical windows of $\mathrm{RMIm}(\mathrm{HF})_{2.3} \mathrm{Fs}$ determined by cyclic voltammetry are slightly changed with the length of the alkyl side-chain on the cation, they are more or less $3 \mathrm{~V}$ that is narrower than those of 1,3-dialkylimidazolium RTILs combined with the other anions. The improvement of electrochemical stability of RTIL electrolytes is indispensable to increase the energy and power density of the electrochemical devices such as electric double layer capacitors (EDLCs). ${ }^{16}$ In the present study, non-aromatic cations, $N$-alkyl- $N$-methylpyrrolidinium $\left(\mathrm{RMPyr}^{+}\right)$and $N$-alkyl- $N$-methylpiperidinium $\left(\mathrm{RMPip}^{+}\right)$shown in Fig. 1, having high electrochemical stabilities are combined with fluorohydrogenate anions, which gives RTILs high conductivities and low melting points. 


\section{Experimental}

Synthesis

$N$-methylpyrrolidine (Aldrich, purity $97 \%$ ), $N$-methylpiperidine (Wako Pure Chemical Industries, purity > $99 \%$ ) and chloroalkanes (1-chlorobutane, Wako Pure Chemical Industries, purity > $98 \%$, 1-chloropropane, Aldrich, purity $98 \%$, chloroethane, Aldrich, purity $>99.7 \%$, chloromethane and Sumitomo Seika Chemicals, purity > $99 \%$ ) were used as supplied. Acetonitrile (Wako Pure Chemical Industries, purity > $99 \%$ ) and ethylacetate (Wako Pure Chemical Industries, purity > 99 \%) which were dehydrated before purchase (water content $<50 \mathrm{ppm}$ ) were used. For the syntheses of $N$-butyl- $N$-methylpyrrolidinium chloride (BMPyrCl), $N$-methyl- $N$-propylpyrrolidinium chloride (PMPyrCl), N-butyl- $N$-methylpiperidinium chloride (BMPipCl) and $N$-methyl- $N$-propylpiperidinium chloride (PMPipCl), the corresponding $N$-methylated amine was added into a mixture of chloroalkane and acetonitrile in an Erlenmeyer flask with an air-tight cap. Then the mixture was reacted at 330-340 K for three days. For the syntheses of $N$-ethyl- $N$-methylpyrrolidinium chloride (EMPyrCl) and $N$-ethyl- $N$-methylpiperidinium chloride (EMPipCl), chloroethane was condensed on the mixture of the corresponding $N$-methylated amine and acetonitrile in a sealed screw-top pressure tube (Ace Glass). The mixture was reacted at $323 \mathrm{~K}$ for one week. 
$N, N$-dimethylpyrrolidinium chloride (DMPyrCl) and $N, N$-dimethylpiperidinium chloride (DMPipCl) were prepared by the same method for the preparation of EMPyrCl and EMPipCl except for the reaction temperature and time (298 K for three days). The obtained chlorides were washed with ethylacetate and dried at $343 \mathrm{~K}$ for one week. RMPyr $(\mathrm{HF})_{n}$ Fs and RMPip(HF $)_{n}$ Fs were prepared by room temperature reactions of RMPyrCls and RMPipCls, respectively, with large excess of anhydrous HF (aHF, Daikin Industries, purity > $99 \%$, dried over $\mathrm{K}_{2} \mathrm{NiF}_{6}$ (Ozark Mahoning)) in a reaction tube made of tetrafluoroethylene-perfluoroalkylvinylether copolymer (PFA). Elimination of the volatile gases and addition of fresh HF were repeated several times for complete elimination of chloride in the form of hydrogen chloride from the reaction product. Finally, volatile gases were eliminated by pumping with a rotary pump (attainable vacuum $1 \mathrm{~Pa}$ ).

\section{Analyses}

Electrochemical measurements were performed with the aid of Hokuto Denko HZ-3000 electrochemical measurement system using glassy carbon rods as working and counter electrodes. A reference electrode was made of silver wire immersed in 1-ethyl-3-methylimidazolium tetrafluoroborate $\left(\mathrm{EMImBF}_{4}\right)$ containing $0.05 \mathrm{M} \mathrm{AgBF}_{4}$ 
and separated from the test cell by Polyflon filter (Advantec PF050). ${ }^{17}$ The potential was referenced to the ferrocenium/ferrocene redox couple dissolved in the RTIL. Conductivity was measured by an impedance technique using a cell with platinum disk electrodes calibrated by $\mathrm{KCl}$ standard aqueous solution. Viscosity measurement was performed using an Ostwald viscometer made of PFA. Density was measured by weighing the sample in a calibrated PFA vessel. The IR spectra were obtained by FTS-165 (BIO-RAD Laboratories). The samples were sandwiched with a pair of AgCl windows fixed in a stainless airtight cell. ${ }^{1} \mathrm{H}-\mathrm{NMR}$ measurements of the samples were performed using a Varian Gemini-300 NMR spectrometer (300 MHz) and the obtained spectra were referenced to tetramethylsilane. ${ }^{19} \mathrm{~F}-\mathrm{NMR}$ measurements of the samples were performed using a Varian Gemini-300 NMR spectrometer (282 MHz) and the obtained spectra were referenced to trichlorofluoromethane. $\mathrm{C}_{6} \mathrm{D}_{6}$ was used as an external standard for the measurements of the neat salts. Differential scanning calorimetric analysis (DSC) was performed on the sample in a nickel cell under nitrogen gas flow using the Shimadzu DSC-60. The scanning rate was $5 \mathrm{~K} \mathrm{~min}^{-1}$.

\section{Results and discussion}

Selected physical properties of RMPyr(HF) ${ }_{2.3}$ Fs and RMPip $(\mathrm{HF})_{2.3}$ Fs are summarized in 
Table 1 with the data of EMIm(HF) ${ }_{2.3} \mathrm{~F}$ for comparison. ${ }^{12}$ In the cases of the reactions of EMPyrCl, PMPyrCl, BMPyrCl, EMPipCl, PMPipCl and BMPipCl with aHF, the vacuum stable composition of the obtained RTILs at room temperature was again formulated by $\mathrm{RMPyr}(\mathrm{HF})_{2.3} \mathrm{~F}$ and $\mathrm{RMPip}(\mathrm{HF})_{2.3} \mathrm{~F}$, respectively, as in the cases of RMIm(HF $)_{2.3}$ Fs. $^{12}$ IR spectra of EMPyr(HF $)_{2.3} \mathrm{~F}$ and EMPip(HF) ${ }_{2.3} \mathrm{~F}$ are shown in Fig. 2. All the RMPyr(HF) ${ }_{2.3}$ Fs and RMPip(HF $)_{2.3}$ Fs exhibit the IR spectra characterized by the absorption bands assigned to the corresponding cations and the fluorohydrogenate anions, $(\mathrm{HF})_{2} \mathrm{~F}^{-}$and $(\mathrm{HF})_{3} \mathrm{~F}^{-}$shown in Fig. 1, as were found in the IR spectra of

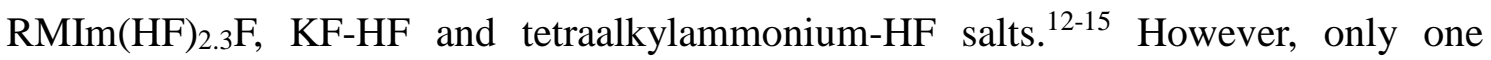
signal is observed in the ${ }^{1} \mathrm{H}-\mathrm{NMR}$ and ${ }^{19} \mathrm{~F}-\mathrm{NMR}$ spectra of these salts suggesting the HF exchange between the anions in shorter time ranges than NMR time scale. ${ }^{11}$ DSC curves of EMPyr(HF $)_{2.3} \mathrm{~F}$, EMPip(HF) $)_{2.3} \mathrm{~F}$ and BMPip(HF $)_{2.3} \mathrm{~F}$ are shown in Fig. 3. For EMPyr $(\mathrm{HF})_{2.3} \mathrm{~F}$, no peaks assigned to crystallization or glass transition are observed in the cooling process from room temperature to $153 \mathrm{~K}$ or the heating process. DSC curves obtained for PMPyr $(\mathrm{HF})_{2.3} \mathrm{~F}$ and $\mathrm{BMPyr}(\mathrm{HF})_{2.3} \mathrm{~F}$ were similar to that for $\mathrm{EMPyr}(\mathrm{HF})_{2.3} \mathrm{~F}$. Two peaks of crystallization in the cooling process and the corresponding two peaks of melting in the heating process are observed for EMPip $(\mathrm{HF})_{2.3} \mathrm{~F}$. Taking their composition into account, they are assigned to the crystallization and melting of 
EMPip $(\mathrm{HF})_{2} \mathrm{~F}$ and EMPip(HF) $)_{3} \mathrm{~F}$, respectively. For BMPip(HF) ${ }_{2.3} \mathrm{~F}$, the glass transition was observed at $162 \mathrm{~K}$ and PMPip(HF) ${ }_{2.3} \mathrm{~F}$ exhibits the similar DSC curve to that of BMPip(HF) $)_{2.3}$ F. All the salts above gradually release HF at elevated temperatures and decompose at around $500 \mathrm{~K}$. The reaction product of $\mathrm{DMPyrCl}$ or DMPipCl and aHF gives a gummy solid after evacuation at room temperature. These compounds are formulated to be DMPyrF-2HF and DMPipF-2HF from the result of elemental analysis, which are probably DMPyr(HF) $)_{2} F$ and DMPip(HF) $)_{2}$ F. DSC curves for these compounds were technically difficult to obtain due to their strong hygroscopicities. $\mathrm{DMPyr}(\mathrm{HF})_{2} \mathrm{~F}$ sealed in a glass capillary immersed in an oil bath melts at $320 \mathrm{~K}$, whereas DMPip(HF) $)_{2} \mathrm{~F}$ melts at $350 \mathrm{~K}$. As mentioned above, nonaromatic cation-based salts usually exhibit high melting points compared to aromatic cation-based salts with similar molecular weights. The melting points (or glass transition points) of RMPyr(HF) ${ }_{n} \mathrm{Fs}$ and RMPip(HF $)_{n}$ Fs found in the present study are exceptionally low.

Arrhenius plots of the conductivities of $\mathrm{RMPyr}(\mathrm{HF})_{2.3} \mathrm{~F}$ and $\mathrm{RMPip}(\mathrm{HF})_{2.3} \mathrm{~F}$ in Fig. 4 exhibit almost linear in the measured temperature range. The conductivity of $\mathrm{RMPyr}(\mathrm{HF})_{2.3} \mathrm{~F}$ is comparable to or a little lower than that of $\mathrm{RMIm}(\mathrm{HF})_{2.3} \mathrm{~F}$ with similar molecular weight and higher than that of RMPip(HF) ${ }_{2.3} \mathrm{~F}$. Among the RTILs prepared for the first time in the present study, EMPyr $(\mathrm{HF})_{2.3} \mathrm{~F}\left(\mathrm{M} . \mathrm{W} .{ }^{=} 179\right)$ exhibits 
the highest conductivity of $74.6 \mathrm{mS} \mathrm{cm}^{-1}$ which significantly exceeds those of non-fluorohydrogenate RTILs. Low viscosities of these salts provide their high conductivities. $^{12}$

Cyclic voltammograms of glassy carbon electrodes in $\mathrm{RMPyr}(\mathrm{HF})_{2.3} \mathrm{Fs}$ and RMPip $(\mathrm{HF})_{2.3} \mathrm{Fs}$ are shown in Fig. 5 with that in $\mathrm{EMIm}(\mathrm{HF})_{2.3} \mathrm{~F}$ for comparison. The anodic and cathodic limits are determined as the potentials where the absolute values of the current densities exceed $0.5 \mathrm{~mA} \mathrm{~cm}{ }^{-2}$ at the scan rate of $10 \mathrm{mV} \mathrm{s}^{-1}$. The electrochemical windows of $\mathrm{RMPyr}(\mathrm{HF})_{2.3} \mathrm{Fs}$ and $\mathrm{RMPip}(\mathrm{HF})_{2.3} \mathrm{Fs}$ are around $5 \mathrm{~V}$, which are much wider than those for $\mathrm{RMIm}(\mathrm{HF})_{2.3} \mathrm{~F}$ (around $3 \mathrm{~V}$ ). For all the RTILs examined in the present study, the contribution of the shift of anodic limits to the extension of the electrochemical windows are significant. As mentioned in the introduction and the previous study, alkylated pyrrolidinium cations possesse high electrochemical stabilities compared to aromatic cations. ${ }^{4,5}$ Unfortunately, no report on the electrochemical stability of alkylated piperidinium cations are so far available. The resistances of RMPyr and RMPip cations against oxidation are suggested to be similar from the similar anodic limit potential.

RTILs in the present study possess relatively high conductivities and some of them exhibit the wide liquid-phase temperature ranges, especially toward the low temperature 
side. RMPyr $(\mathrm{HF})_{2.3} \mathrm{Fs}$ exhibit higher conductivities than RMPip(HF) ${ }_{2.3}$ Fs, whereas the electrochemical windows of both are similar, around $5 \mathrm{~V}$.

Thus the fluorohydrogenate salts in this study are expected to be applied for electrolytes of electrochemical devices such as EDLC and electrolytic baths for electrochemical fluorination. Detailed studies on the physicochemical properties and structures of $\mathrm{DMPyr}(\mathrm{HF})_{2} \mathrm{~F}$ and $\mathrm{DMPip}(\mathrm{HF})_{2} \mathrm{~F}$ as well as practical applications are now under way.

The authors would like to thank to Dr. Kunitaka Momota (Morita Chemical Industries) for his kind help about experimental techniques. The authors wish to express their gratitude to Associate Professor Seijiro Matsubara and Mr. Hideaki Yoshino to their help for the NMR measurements. One of the authors, Kazuhiko Matsumoto, thanks to the Japan Society for the Promotion of Science for the financial support to the research fellow. This work was supported by a Grant in Aid for Scientific Research by the Japan Society for the Promotion of Science (No. 13555237) and the 21th Century COE Program "Establishment of COE on Sustainable-Energy System" from Japanese Ministry of Education, Culture, Sports, Science and Technology. 


\section{References}

(1) T. Welton, Chem. Rev., 99, 2071 (1999).

(2) R. Hagiwara, Y. Ito, J. Fluorine Chem., 105, 221 (2000).

(3) J. S. Wilkes, J. A. Levisky, R. A. Wilson and C. L. Hussey, Inorg. Chem., 21, 1263 (1982).

(4) S. Forsyth, J. Golding, D. R. MacFarlane, M. Forsyth, Electrochim. Acta, 46, 1753 (2001).

(5) D. R. MacFarlane, P. Meakin, J. Sun, N. Amini, M. Forsyth, J. Phys. Chem. B, 103, 4164 (1999).

(6) J. Sun , D. R. MacFarlane, M. Forsyth, J. Mater. Chem., 11, 2940 (2001).

(7) H. Matsumoto, H. Kageyama and Y. Miyazaki, Chem. Commun., 2002, 1726.

(8) R. C. Carlin, H. C. De Long, L. F. Fuller, P. C. Trulove, J. Electrochem. Soc., 141, L73 (1994).

(9) P. Bonhôte, A. -P. Dias, M. Armand, N. Papageorgiou, K. Kalyanasundaram and M. Grätzel, Inorg. Chem., 35, 1168 (1996).

(10) R. Hagiwara T. Hirashige, T. Tsuda, Y. Ito, J. Fluorine Chem., 99, 1 (1999).

(11) R. Hagiwara, T. Hirashige, T. Tsuda, Y. Ito, J. Electrochem. Soc., 149, D1 (2002).

(12) R. Hagiwara, K. Matsumoto, Y. Nakamori, T. Tsuda, Y. Ito, H. Matsumoto, K. 
Momota, J. Electrochem. Soc., 150, D195 (2003).

(13) J. H. Clark, J. Emsley, D. J. Jones and R. E. Overrill, J. Chem. Soc., Dalton Trans., 1981, 1219.

(14) T. v. Rosenvinge, M. Parrinello and M. L. Klein, J. Chem. Phys., 107, 8013 (1997).

(15) I. Gennick, K. M. Harmon and M. M. Potvin, Inorg. Chem., 16, 2033 (1977).

(16) A. B. McEwen, H. L. Ngo, K. LeCompte, J. L. Goldman, J. Electrochem. Soc., 146, 1687 (1999).

(17) K. Momota, M. Morita, and Y. Matsuda, Electrochim. Acta., 38, 619 (1993). 
Table1 Selected physical and electrochemical properties of room temperature vacuum stable RMPyr(HF) $)_{2.3} \mathrm{~F}$ and RMPip(HF $)_{2.3} \mathrm{~F}$

\begin{tabular}{|c|c|c|c|c|c|c|c|c|}
\hline \multirow{3}{*}{ EMPyr $(\mathrm{HF})_{2.3} \mathrm{~F}$} & \multirow{3}{*}{$\begin{array}{l}\text { M.W. } \\
179\end{array}$} & \multirow{3}{*}{$\begin{array}{l}\frac{T_{m}}{/ \mathrm{K}} \\
<145\end{array}$} & \multirow{3}{*}{$\begin{array}{l}\frac{\rho}{/ \mathrm{g} \mathrm{cm}^{-3}} \\
1.07\end{array}$} & \multirow{3}{*}{$\begin{array}{c}\frac{\eta}{1 \mathrm{cP}} \\
9.9\end{array}$} & \multirow{3}{*}{$\frac{\sigma}{\frac{\sigma}{/ \mathrm{mS} \mathrm{cm}^{-1}}} \frac{74.6}{}$} & \multirow{3}{*}{$\begin{array}{l}\frac{E_{a}}{/ \mathrm{kJ} \mathrm{mol}^{-1}} \\
10.1\end{array}$} & \multirow{2}{*}{\multicolumn{2}{|c|}{$\frac{E_{a n} \quad E_{c a t}}{/ \mathrm{V} v \mathrm{~s} . \mathrm{Fc}^{+} / \mathrm{Fc}}$}} \\
\hline & & & & & & & & \\
\hline & & & & & & & 2.67 & -1.99 \\
\hline $\operatorname{PMPyr}(\mathrm{HF})_{2.3} \mathrm{~F}$ & 193 & $<145$ & 1.05 & 11.2 & 58.1 & 10.9 & 2.78 & -2.56 \\
\hline $\mathrm{BMPyr}(\mathrm{HF})_{2.3} \mathrm{~F}$ & 207 & $<145$ & 1.04 & 14.5 & 35.9 & 12.1 & 2.38 & -2.33 \\
\hline EMPip $(\mathrm{HF})_{2.3} \mathrm{~F}$ & 193 & 217,237 & 1.07 & 24.2 & 37.2 & 13.4 & 2.81 & -2.33 \\
\hline PMPip(HF) $)_{2.3} \mathrm{~F}$ & 207 & $164\left(T_{g}\right)$ & 1.06 & 33.0 & 23.9 & 16.2 & 2.87 & -2.35 \\
\hline BMPip $(\mathrm{HF})_{2.3} \mathrm{~F}$ & 221 & $162\left(T_{g}\right)$ & 1.04 & 37.1 & 12.3 & 22.6 & 2.52 & -2.81 \\
\hline $\operatorname{EMIm}(\mathrm{HF})_{2.3} \mathrm{~F}^{\mathrm{a}}$ & 176 & $148\left(T_{g}\right), 208$ & 1.13 & 4.9 & 100 & 10.1 & 1.26 & -1.83 \\
\hline
\end{tabular}

M.W.: molecular weight, $T_{m}$ : melting point, $T_{g}$ : glass transition temperature, $\rho$ : density, $\eta$ : viscosity, $\sigma$ : conductivity, $E_{a}$ : activation energy of conductivity, $E_{a n}$ : anodic limit, $E_{\text {cat }}$ : cathodic limit. ${ }^{\text {a }}$ ref [12]. 


\section{Figure captions}

Fig. 1 Molecular structures of (a) $\mathrm{RMPyr}^{+}$, (b) $\mathrm{RMPip}^{+}$, (c) (HF) $)_{2} \mathrm{~F}^{-}$and (d) (HF) $)_{3} \mathrm{~F}^{-}$.

Fig. 2 IR spectra of (a) EMPyr(HF) ${ }_{2.3} F$ and (b) EMPip(HF) $)_{2.3} F$.

Fig. 3 DSC curves of (a) EMPyr(HF) ${ }_{2.3} F$, (b) EMPip(HF) ${ }_{2.3} F$ and (c) BMPip(HF) ${ }_{2.3} F$.

Fig. 4 Arrhenius plots of the conductivities for $\circ$ : EMPyr $(\mathrm{HF})_{2.3} \mathrm{~F}, \square: \operatorname{PMPyr}(\mathrm{HF})_{2.3} \mathrm{~F}, \diamond$ :

$\operatorname{BMPyr}(\mathrm{HF})_{2.3} \mathrm{~F}$, x: EMPyr(HF) ${ }_{2.3} \mathrm{~F},+$ : $\mathrm{PMPyr}(\mathrm{HF})_{2.3} \mathrm{~F}$ and $\Delta$ : BMPyr $(\mathrm{HF})_{2.3} \mathrm{~F}$.

Fig. 5 Cyclic voltammograms of glassy carbon electrodes immersed in (a)

EMPip(HF) $)_{2.3} F$, (b) $\operatorname{PMPip}(\mathrm{HF})_{2.3} \mathrm{~F}, \quad$ (c) $\quad \operatorname{BMPip}(\mathrm{HF})_{2.3} \mathrm{~F} \quad$ (d) $\operatorname{EMPyr}(\mathrm{HF})_{2.3} \mathrm{~F}, \quad$ (e) PMPyr(HF) ${ }_{2.3} F$, (f) BMPyr(HF) $)_{2.3} F$ and (g) EMIm(HF) 2.3 F. C. E.: glassy carbon, R. E.: Ag wire immersed in $\mathrm{EMImBF}_{4}$ containing $0.05 \mathrm{M} \mathrm{AgBF}_{4}$. Potential is referenced to the redox potential of ferrocenium/ferrocene couple. 
<smiles>[R][N+]1(C)CCCC1</smiles>

(a)<smiles>FCPF</smiles>

(c)<smiles>[R][N+]1([14CH3])CCCCC1</smiles>

(b)<smiles>F[10PH]PC(F)F</smiles>

(d) 


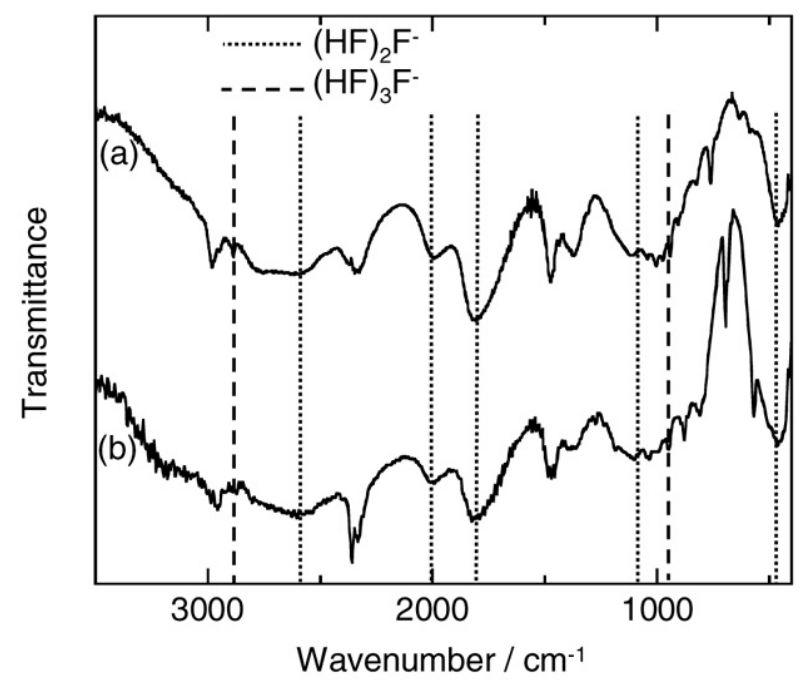




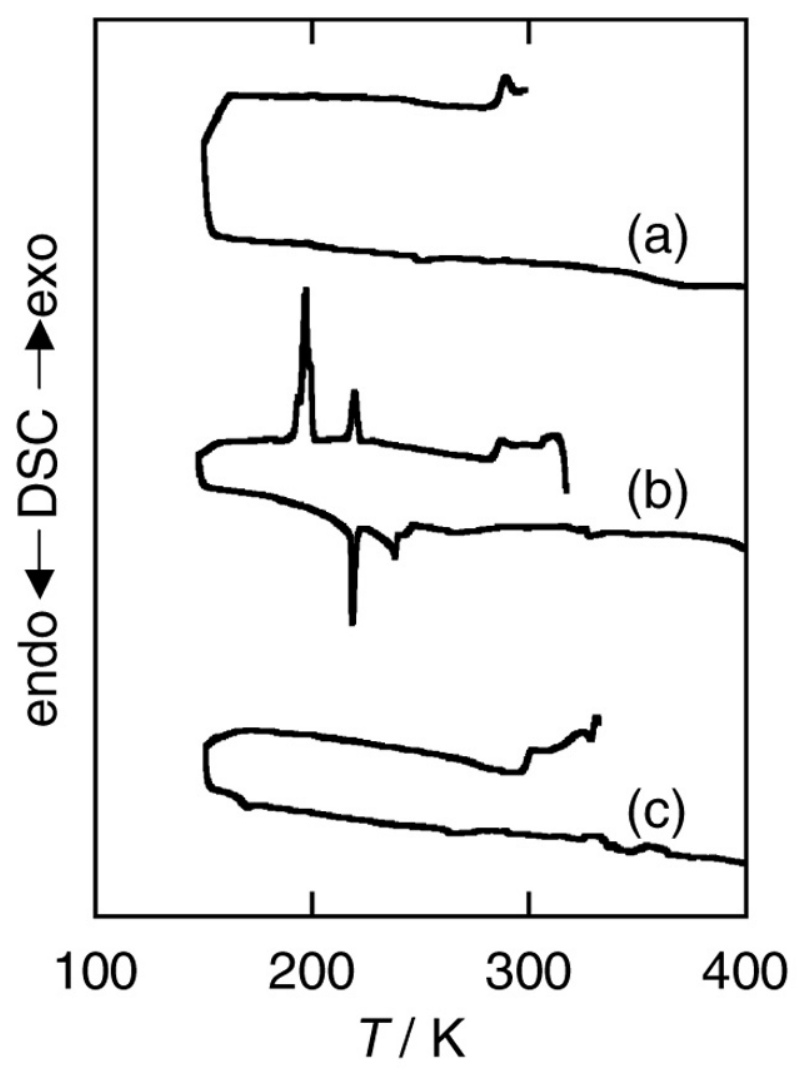




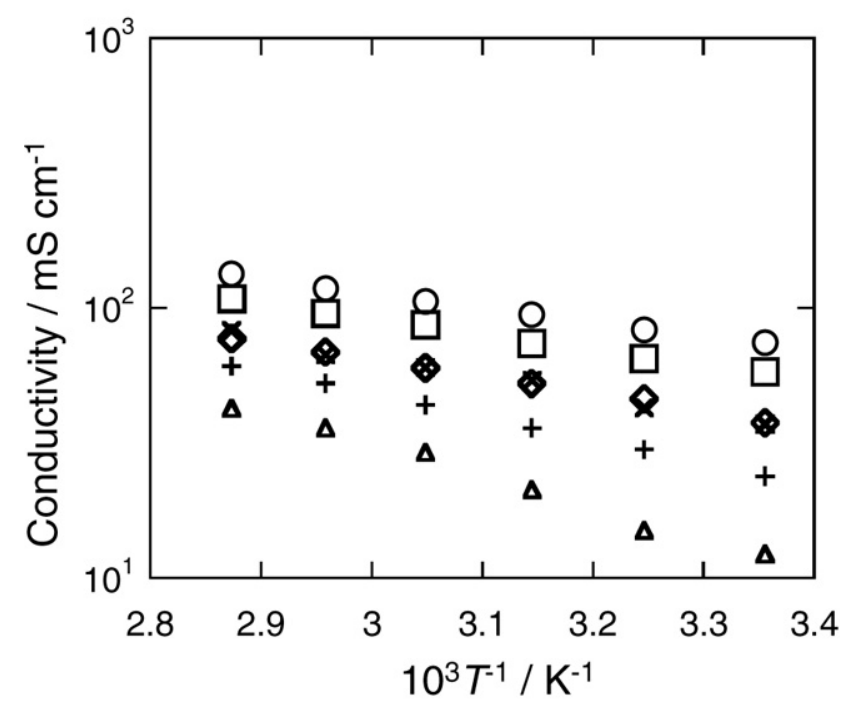




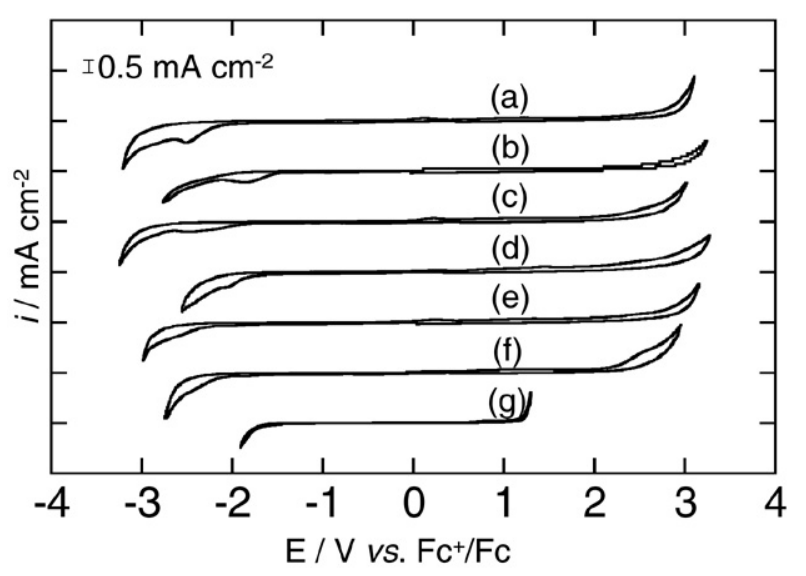

